\title{
O currículo das escolas brasileiras na década de 1970: novas perspectivas historiográficas
}

\author{
Beatriz Boclin Marques dos Santos*
}

\section{Resumo}

Fundamentado na Lei $n^{0}$ 5.692, de 11 de agosto de 1971, que fixou as Diretrizes e Bases para o ensino de $1^{\circ}$ e $2^{\circ}$ graus e no Parecer 853/71, este artigo apresenta uma pesquisa histórico-documental desenvolvida no Programa de Pós-graduação em Educação, na Universidade Federal do Rio de Janeiro. Trata-se de uma análise das ideias pedagógicas desenvolvidas ao longo da década de 1960, sob a influência dos educadores da Escola Nova, e sua contribuição para os fundamentos da Reforma Educacional, que incluiu a disciplina no currículo de $1^{\circ}$ e $2^{\circ}$ graus de nossas escolas. A partir de uma nova perspectiva historiográfica que o distanciamento torna possível, esta pesquisa constatou que a implantação dos Estudos Sociais no ensino de primeiro grau refletiu um desdobramento da legislação do Conselho Federal de Educação, em vigor desde 1966. A composição do Conselho na década de 60, incluindo nomes significativos da Escola Nova no Brasil, veio confirmar que a adoção dos Estudos Sociais como disciplina no currículo baseou-se em uma questão eminentemente pedagógica.

Palavras-chave: Currículo. Disciplinas Escolares. Escola Nova. Estudos Sociais.

\section{Introdução}

O presente estudo fundamenta-se nos resultados de pesquisa desenvolvida no Programa de Pós-graduação em Educação, para conclusão de tese de doutorado na Universidade Federal do Rio de Janeiro. Destacamos que se trata de uma pesquisa histórico-documental, com base na documentação referente à Lei $\mathrm{n}^{\mathrm{o}}$ 5.692, de 11 de agosto de 1971 (BRASIL, 1971) que Fixou as Diretrizes e Bases para o ensino de $1^{\circ}$ e $2^{\circ}$ graus do Ministério da Educação e Cultura, e no Parecer 853/71, conforme exposto na Bibliografia. Lembramos que o Parecer 853 explica a fundamentação pedagógica e filosófica da Legislação Educacional que entrava em vigor. O depoimento da Professora Terezinha Saraiva complementou, corroborou

\footnotetext{
* Doutorado em Educação, UFRJ. Coordenadora do Núcleo de Documentação e Memória do Colégio Pedro
} II, Rio de Janeiro. E-mail: bmarquesdossantos@gmail.com 
e ampliou o conhecimento revelado pelas fontes documentais/primárias utilizadas na pesquisa, uma vez que a Professora foi Conselheira da Câmara do Ensino de $1^{\circ}$ e $2^{\mathrm{a}}$ graus e participou ativamente da elaboração da nova Lei de Diretrizes e Base.

As conclusões da pesquisa ressaltam a ruptura de uma visão que se perpetuou no meio acadêmico, especialmente no campo da História de que a Reforma Educacional da década de 1970 e as idéias envolvidas na concepção pedagógica de ensino da época, reportavam-se exclusivamente a uma diretiva do governo militar, para a educação, priorizando questões de cunho ideológico e político. Nas investigações, cujos resultados estão expressos no presente artigo, destacamos o fato de que a criação da disciplina escolar Estudos Sociais não resultou da interferência nem teve uma relação direta com diretrizes do então governo militar. A resistência e crítica suscitadas expressam embates entre concepções sobre currículo e tradições estabelecidas, com repercussões sobre a formação de professores. A contribuição do artigo para a História da Educação está no fato de revelar a partir de pesquisa documental complementada pelo testemunho da Professora Terezinha Saraiva, os bastidores da Reforma Educacional da década de 1970 e o comprometimento dos legisladores, em primeira instância, com as questões pedagógicas.

O tema em questão não foi polêmico apenas na década de 1970, no momento atual especialmente após a publicação pelo Ministério da Educação e Cultura da nova proposta de fusão de disciplinas no Ensino Médio, incluindo, dessa forma, alguns pressupostos da Lei 5.692/1971, como a “integração de conteúdos", tornase fundamental, no cenário educacional brasileiro atual, rever os fundamentos da Reforma Educacional da década de 1970.

\section{Lei $\mathbf{n}^{\circ} \mathbf{5 . 6 9 2 / 7 1}$ de 11 de agosto de 1971}

A Lei $\mathrm{n}^{\circ} 5.692^{1}$, de 11 de agosto de 1971, estabeleceu as diretrizes e bases para o ensino de primeiro e segundo graus, conforme a nova terminologia para os antigos cursos primário, ginasial e colegial. Na década de 70, esse documento apresentou as novas propostas para esses níveis de educação.

A Lei 5.692 estabelecia, no Capítulo I-Do Ensino de $1^{\circ}$ e $2^{\circ}$ graus, os objetivos para o ensino que corresponderia, hoje, à educação básica - excetuando a educação infantil:

1 (BRASIL, 1971a). Congresso Nacional. Lei n 5.692 de 11.8.1971 - Fixa diretrizes e bases para o ensino de $1^{\circ}$ e $2^{\circ}$ graus e dá outras providências. 


\begin{abstract}
Art. $1^{\circ}$. O ensino de $1^{\circ}$ e $2^{\circ}$ grau tem por objetivo geral proporcionar ao educando a formação necessária ao desenvolvimento de suas potencialidades como elemento de auto-realização, qualificação para o trabalho e preparo para o exercício consciente da cidadania. $\S 1^{\circ}$ Para efeito do que dispõem os arts. 176 e 178 da Constituição, entende-se por ensino primário a educação correspondente ao ensino de primeiro grau e por ensino médio, o de segundo grau. (BRASIL, 1971).
\end{abstract}

Os estudos para a reforma do ensino de $1^{\circ}$ e $2^{\circ}$ graus tiveram início em 1969, a partir da elaboração de dois pareceres do Conselho Federal de Educação - os de números 466/69 e 793/69 - de autoria do Conselheiro Celso Kelly, resultando na formação do primeiro Grupo de Trabalho ${ }^{2}$ a apresentar sugestões para a reformulação dos ensinos primário e médio (este correspondendo ao ginasial e ao colegial da época (SARAIVA, 1984).

A Prof ${ }^{a}$ Terezinha Saraiva ${ }^{3}$, Conselheira do Conselho Federal de Educação de 1970 a 1980, relata em entrevista para esta pesquisa que sua participação na elaboração da Lei 5.692 teve origem no Grupo de Trabalho organizado em 1969 pelo Ministro da Educação e Cultura, Tarso Dutra, atendendo ao indicativo do Parecer 466/69. Esse Parecer, assim como o de $n^{\circ} 793 / 69$, tinham como objetivo propor uma revisão da LDB 4.024/61 no que se referisse a esses dois graus de ensino com base em alguns "pontos de vista", os quais, na prática, revelavam concepções e princípios que foram mais tarde incorporados pela Lei 5.692. Desde 1969 já havia um grupo de educadores participando de um grupo de trabalho criado para pensar e elaborar uma nova proposta envolvendo esses dois graus de ensino.

No Parecer 466/69 do Conselho Federal de Educação já se vislumbravam alguns dos princípios encontrados na Lei 5.692, como o fim do exame de admissão e a

2 Criado pelo Decreto 65.189 de set. 1969, foi instituído o primeiro Grupo de Trabalho formado por 20 educadores para "propor reformas no ensino fundamental". O Grupo compunha-se dos seguintes membros: Alberto Mesquita de Carvalho; Alfredina de Paiva e Souza; Carlos Pasquale; Carlos Ribeiro Mosso; Clélia de Freitas Capanema; Cora Bastos de Freitas Rachid; Gildásio Amado; Jayme Abreu; Jorge Barifaldi Hirs; José Augusto Dias; Padre José Vieira de Vasconcellos; Letícia Maria Santos de Faria; Linda Ganej Andrade; Lucia Marques Pinheiro; Luiz Gonzaga Ferreira; Maria Clarice Pereira Fonseca; Nise Pires; Roberto Hermeto Corrêa da Costa; Terezinha Saraiva; e Vandick Londres da Nóbrega (Diretor Geral do Colégio Pedro II).

3 Conselheira do Conselho Estadual de Educação do Rio de Janeiro e do antigo Conselho Federal de Educação. Membro da Câmara de Ensino de $1^{\circ}$ e $2^{\circ}$ Graus do Conselho Federal de Educação (1971 e 1980). Membro da Academia Brasileira de Educação e da Academia Internacional de Educação. Participou da elaboração da Lei n 5.692 e da LDB de 1996, integrando um GT constituído pelo presidente do Conselho Federal de Educação à época, professor Fernando Gay da Fonseca. Esse grupo reuniu-se durante dois meses no Colégio São Bento do Rio de Janeiro, tendo então encaminhado ao CFE um anteprojeto de lei relacionado à revisão da LDB de 1961. 
continuidade dos estudos do antigo primário no ginásio, além da preocupação de que o ensino tivesse como eixo a integração do homem ao meio em que vive:

O $1^{\circ}$ ciclo - o ginásio - é mais um trecho da mesma estrada iniciada com a escola primária. Nem uma nem outra devem perder-se nas abstrações infecundas: ambas têm diante de si a vida da criança e a dinâmica da comunidade. Cobrem faixas etárias diversas, mas colimam fins semelhantes... abrindo os horizontes da cultura geral, no âmbito do primário ao ginásio, os sistemas de ensino estão cuidando, básica e essencialmente do homem e no seu ajustamento ao meio e ao tempo. (SARAIVA, 1984, p. 20)

Os trabalhos desenvolvidos pelo Grupo, formado em 1969 por 21 membros, sugeriram em seu relatório conclusivo algumas diretrizes a serem adotadas na reforma do ensino fundamental e médio de 1971, como podemos constatar por algumas das indicações apontadas pelos seus membros (SARAIVA, 1984, p. 20): identado

- Integração do ensino primário e médio dentro de objetivos comuns por meio de processos adequados às idades sucessivas;

- A integração do ensino fundamental no meio físico e social, assegurando a plenitude da formação humana;

- Compreensão da realidade - trabalho entre os problemas comuns do meio e do homem, a partir das últimas séries do ensino primário e ao longo do ginásio, sem caráter profissionalizante, mas como exploração e estímulo das vocações e como processo de objetivação dos problemas sociais e econômicos que envolvem o educando.

Por sua vez, o Parecer 793/69 seguia as recomendações dadas pela IV Conferência Nacional de Educação, ressaltando que o curso ginasial deveria ser a continuação do curso primário: ambos integrados, porém com maior profundidade.

O que se estimava era encontrar a continuidade de formação e de estudos que, iniciada aos 7 anos, o acompanhasse até os 14 anos, correspondendo plenamente à faixa etária considerada de ensino obrigatório pela Constituição do Brasil. (SARAIVA, 1984 p. 20).

A nova filosofia que se delineava nos dois pareceres representou a essência de algumas inovações da Lei 5.692, como por exemplo, as "matérias" Estudos 
Sociais, Comunicação e Expressão e Ciências, que substituíram as disciplinas tradicionais no primeiro grau, assim como já acontecia no primário. Isso nos faz ver que havia uma perspectiva de continuidade dos estudos do primário para o ginásio - agora primeiro grau.

O Ministro da Educação e Cultura, Jarbas Gonçalves Passarinho, em entrevista para o Jornal O Globo 11 de junho de 1971, explicou a proposta inserida no anteprojeto de reforma do ensino fundamental:

"O ensino de primeiro grau vai ser chamado de ensino fundamental também. Ele é o ensino em 8 anos. Para conceituar para o grande público, seria - não é, mas usando a imagem para conceituar - como se nós somássemos os quatro anos do primário de hoje com os quatro anos do atual ginásio. Mas nós queremos muito mais que justaposição. Queremos integração, tanto vertical como horizontal desses oito anos. E mais ainda: que desde logo dê noções úteis para a vida."

Em 1970, o Ministro Jarbas Passarinho havia criado um novo Grupo de Trabalho ${ }^{4}$, com o objetivo de elaborar o anteprojeto da Lei 5.692. Como explica a Prof ${ }^{a}$ Terezinha Saraiva:

"Fiquei no Conselho Federal de Educação de 1970 a 1980. Tive dois mandatos no Conselho. No primeiro mandato, ocupei a vaga do professor Carlos Pasquale, que havia falecido, e completei o tempo dele que era de quatro anos. Logo a seguir o ministro Passarinho reconduziu-me ao cargo e permaneci por mais 6 anos. Quando entrei no Conselho Federal de Educação estava sendo discutido o anteprojeto da Lei de reforma de primeiro e segundo graus. O Ministro havia recebido em dezembro de 1969 o relatório do primeiro GT. Depois constituiu um grupo menor do qual faziam parte: Valnir Chagas, Eurides Brito, Pe. José Vieira de Vasconcellos ${ }^{5}$, Nise Pires, Clélia Capanema, Gildásio Amado, Aderbal Jurema, Geraldo Bastos Silva, Magda Soares. Esse Grupo trabalhou em cima do primeiro relatório, e apresentou o Anteprojeto da Lei 5.692. Este anteprojeto foi enviado pelo Ministro ao Conselho Federal de Educação, que o analisou durante uma semana propondo algumas alterações. Depois, o

4 O Decreto 66.600, de 20.5.1970, instituiu o segundo Grupo de Trabalho, constituído por 9 membros.

5 O Padre José Vieira de Vasconcelos participou dos dois Grupos de Trabalho. 
CFE realizou uma reunião conjunta com os Conselhos Estaduais para análise do anteprojeto. Como se vê, não há amparo para uma das críticas feitas à Lei 5.692/71, que diz que não tinha havido consulta sobre o anteprojeto. $\mathrm{O}$ mesmo foi discutido não só em nível do Conselho Federal como pelos Conselhos Estaduais, além de terem sido ouvidas outras instâncias."

Na proposta apresentada pelo Grupo que elaborou o Anteprojeto de Lei6, o ensino de $1^{\circ}$ grau teria como objetivo, além da educação geral, a sondagem de aptidões e a iniciação para o trabalho, sem ser profissionalizante; quer dizer, priorizava a formação para a vida em sociedade. Nessa concepção, o objetivo da educação visava à formação para o autoconhecimento, entendendo que esse processo ocorria mediante a interação do jovem com o meio em que vive por meio do trabalho e da convivência. Nessa perspectiva, a formação cultural oriunda do processo educativo oferecia os meios para a atuação do aluno no mundo do trabalho e no meio social, contribuindo para a sua realização pessoal (SARAIVA, 1984).

No caderno de Educação do Jornal O Globo do dia 26 de junho de 1971 encontram-se os pontos de vista do então Ministro Jarbas Passarinho sobre a Reforma Educacional que seria implementada. O artigo do jornal trata da conferência que o ministro realizou no dia 25.6.1971 na Escola Superior de Guerra (ESG) sobre o tema O problema educacional no Brasil. Podemos constatar, pelo teor dessa conferência, a aproximação da fala do ministro e o sentido oriundo dos ideais da Escola Nova encontrado nos fundamentos da reforma de ensino, como vimos acima:

"É necessário que se dê à educação, desde o seu início, um conteúdo que permita a preparação para a vida, dentro do verdadeiro humanismo que concilie a formação do indivíduo para o exercício profissional com a visão global da vida que deve possuir. A educação ideal é a que desperta a capacidade de raciocínio com a capacidade de análise crítica."

Questionada sobre o que movia essa proposta e quais eram as suas influências, a Prof ${ }^{a}$ Terezinha Saraiva explicou:

6 O Ministro da Educação encaminhou o anteprojeto ao Conselho Federal de Educação para análise. O CFE reuniu-se durante uma semana, e o resultado dos debates foi encaminhado ao Ministro. Foram sugeridas 65 emendas aditivas, supressivas e substitutivas (SARAIVA, 2004, p. 371). 


\begin{abstract}
"Uma das primeiras propostas era acabar com o Exame de Admissão e fazer uma educação contínua juntando o antigo primário, com o antigo ginásio. Daí nasceu o ensino de $1^{\circ}$ Grau que atualmente corresponde ao Ensino Fundamental. No Grupo de Trabalho que eu participei, a proposta era para um ensino fundamental de nove anos. O grupo posterior havia proposto cinco anos obrigatórios e, se possível, mais três anos. Na reunião plenária do Conselho Federal de Educação foi proposta a duração de oito anos e foi exatamente o que foi aprovado. A intenção era terminar com o obstáculo entre ensino primário e ensino ginasial, que não tinha a menor razão de ser. Sabíamos que haveria dificuldades nesta continuidade com os professores, pois primeiro começaria com as séries de primeiro grau, um professor único, e depois haveria a ramificação para vários professores na segunda etapa."
\end{abstract}

A implementação da Lei 5.692 fixou a duração de oito anos - ou 720 horas de atividades anuais - para o ensino de primeiro grau, abrangendo as quatro séries do antigo ensino primário acrescido de mais quatro séries do ensino ginasial ${ }^{7}$. O ensino de segundo grau passava, então, a compreender os três anos do antigo ensino colegial.

O que consideramos mais significativo nas propostas da Lei 5.692 não são as mudanças no tempo da escolaridade, nem as alterações quanto às designações dos diferentes segmentos do ensino, mas a mudança de concepção de escola e do ensino nela presentes. Pode-se mesmo perceber que há um discurso da pedagogia perpassando a elaboração do currículo de primeiro e segundo graus e interferindo no que seria ensinado pelas disciplinas.

A Lei determinava que os currículos de primeiro e segundo graus fossem constituídos de um núcleo comum obrigatório em nível nacional, e conferia ao Conselho Federal de Educação a atribuição de fixar as matérias relativas a esse núcleo comum, definindo objetivos e amplitude. A parte diversificada dos currículos seria relacionada pelos Conselhos Estaduais de Educação, cabendo às escolas escolherem as disciplinas que constituiriam a parte diversificada, como estabelecido nos Artigos $4^{\circ}$ e $5^{\circ}$ a seguir:

Art.4 ${ }^{o}$. Os currículos do ensino de $1^{\circ}$ e $2^{\circ}$ graus terão um núcleo comum, obrigatório em âmbito nacional, e uma parte diversificada para atender conforme

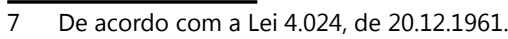


as necessidades e possibilidades concretas, às peculiaridades locais, aos planos dos estabelecimentos e às diferenças individuais dos alunos.

$\S 1^{\circ}$ Observar-se-ão as seguintes prescrições na definição dos conteúdos curriculares:

O Conselho Federal de Educação fixará para cada grau as matérias relativas ao núcleo comum, definindo-lhes os objetivos e a amplitude;

Os Conselhos de Educação relacionarão, para os respectivos sistemas de ensino, as matérias dentre as quais poderá cada estabelecimento escolher as que devem constituir a parte diversificada.

Art 5․ As disciplinas, áreas de estudo e atividades que resultem das matérias fixadas na forma do artigo anterior, com as disposições necessárias ao seu relacionamento, ordenação e sequência, constituirão para cada grau o currículo pleno do estabelecimento.

Consideramos importante observar que a Lei n. 5.692 distinguia claramente o sentido de matéria e de currículo. Nessa proposta não ficava estabelecido um programa de ensino, que seria construído nas escolas. O chamado "currículo pleno" era formado a partir das grandes linhas de matérias que constituíam o núcleo comum $^{8}$ (respeitando a indicação do Conselho Federal de Educação quanto às disciplinas obrigatórias na composição das matérias) acrescido da parte diversificada, conforme diretrizes dos Conselhos Estaduais de Educação e pelos planos de estudo do estabelecimento de ensino, cujos conteúdos eram selecionados pela equipe de professores de acordo com as especificidades do ambiente escolar. Podemos observar uma certa flexibilidade na proposta da lei, uma vez que a escolha dos conteúdos ocorria na escola e o currículo apresentava uma configuração própria, conforme o estabelecimento de ensino. A análise dos dispositivos da lei permite-nos também apontar a presença de um indicativo de que a aprendizagem não se restringia apenas à aquisição de conhecimentos, mas promovia um processo que englobava habilidades, atitudes e criatividade.

Por outro lado, chamamos também a atenção para o uso do termo "matéria" nos Arts. $4^{\circ}$ e $5^{\circ}$ da Lei n. 5.692, que não correspondia ao sentido tradicionalmente

8 Comunicação e Expressão, Estudos Sociais e Ciências. 
dado ao termo; quer dizer, o termo "matéria" não tem o mesmo sentido do termo "disciplina", porquanto a ideia de "matéria" corresponde a um recorte constituído por algumas disciplinas, algo que se vai configurar a partir da forma que receba. Nesse sentido, a matéria é mutável e pode adquirir formas distintas, conforme os conteúdos selecionados nos diferentes níveis de atividades, área de estudo e disciplinas. A perspectiva da lei prevê que o conhecimento apresente-se com formas distintas em cada nível, de modo a atender às necessidades de aprendizagem.

De acordo com o Parecer $853 / 71^{9}$ do Conselho Federal de Educação, de autoria do Conselheiro Valnir Chagas, o sentido dado ao termo "matéria" correspondia a um recorte que englobava algumas disciplinas que deveriam constar no currículo e separava essa versão do currículo pleno, este sim ampliado pela parte diversificada. Os conteúdos que iriam compor as disciplinas formadoras das matérias do núcleo comum (correspondendo ao conteúdo mínimo para uma formação no $1^{\circ}$ e $2^{\circ}$ graus), assim como a parte diversificada, eram escolhidos pelos estabelecimentos de ensino a partir da proposta fixada pelos Conselhos Estaduais de Educação, e variavam conforme as especificidades das regiões e das respectivas escolas, como exposto no Parecer 853 (p.67):

\section{Matéria e currículo.}

De uma das fontes, ou de ambas, ela poderá emanar: do Conselho de Educação de cada sistema de ensino, que relacionará matérias além das do núcleo-comum ( $\operatorname{art} .4^{\circ}, \S 1^{\circ}$, inciso II, e dos próprios estabelecimentos (art. $4^{\circ}, \S 1^{\circ}$, inciso III)).

A Resolução ${ }^{\circ} 8$ do Conselho Federal de Educação, de $1^{\circ}$ de dezembro de 1971, derivada do Parecer 853/71, estabelecia as matérias que formavam o núcleo comum e as disciplinas obrigatórias das matérias fixadas. Nessa Resolução, destacamos também a indicação de que as matérias seriam trabalhadas no currículo de forma integrada e obedecendo a um escalonamento em consonância com o amadurecimento do aluno:

Art. $1^{\circ}$. O núcleo-comum a ser incluído, obrigatoriamente, nos currículos plenos do ensino de $1^{\circ}$ e $2^{\circ}$ graus abrangerá as seguintes matérias:

9 (BRASIL, 1971b). Conselho Federal de Educação. Câmara de Ensino de $1^{\circ} \mathrm{e} 2^{\circ}$ graus. Núcleo-comum para os currículos do ensino de $1^{\circ} \mathrm{e} 2^{\circ}$ Graus. A doutrina do currículo na Lei $n^{\circ} 5.692$. Parecer $n^{\circ} 853 / 71$, aprovado em 12.11.1971. 


\begin{abstract}
a) Comunicação e Expressão
b) Estudos Sociais

c) Ciências

$\S 1^{\circ}$ Para efeito da obrigatoriedade atribuída ao núcleo-comum, incluem-se como conteúdos específicos das matérias fixadas: em Comunicação e Expressão - a Língua Portuguesa; nos Estudos Sociais - a Geografia, a História e a Organização Social e Política do Brasil; nas Ciências - a Matemática e as Ciências Físicas e Biológicas. $\boldsymbol{A r t . 2 ^ { \circ }}$. As matérias fixadas, diretamente e por seus conteúdos obrigatórios, deverão conjugar-se entre si e com outras que se lhes acrescentem para assegurar a unidade do currículo em todas as fases do seu desenvolvimento.

$\operatorname{Art} 4^{o}$. As matérias fixadas nesta Resolução serão escalonadas, nos currículos plenos do ensino de $1^{\circ}$ e $2^{\circ}$ graus, da maior para a menor amplitude do campo abrangido, constituindo atividades, áreas de estudo e disciplinas.
\end{abstract}

Portanto, de acordo com o Artigo $4^{\circ}$ da Resolução $n^{\circ} 8$, que trata do escalonamento proposto para as matérias, o uso do termo "matéria' abrangia as atividades, as áreas de estudo e as disciplinas, de acordo com o nível de aprendizagem para o qual seria trabalhada. As matérias possuíam seus componentes ou disciplinas específicas. Nesse sentido, os Estudos Sociais constituíam uma matéria, e a História e a Geografia eram as disciplinas que a compunham. Uma matéria representava um recorte do conhecimento que constituía o núcleo comum (Parecer 853/71, p. 68):

[...] segundo a sistemática da lei, por aproximações sucessivas e em escala decrescente, numa intencional busca de autenticidade aos vários níveis de influência que se projetam no ensino: o nível dos conhecimentos humanos, o nível nacional, o nível regional, o nível escolar e o nível do próprio aluno... O Grupo de Trabalho responsável pelo anteprojeto básico da lei 5.692, em seu relatório, já salientava que o núcleo-comum e a parte diversificada, mesmo reunidos ainda não constituem propriamente o currículo, e sim a matéria-prima a ser trabalhada no currículo pleno de cada estabelecimento; daí o emprego da palavra matéria nesta fase.

Significa isto que "matéria" é todo campo de conhecimentos fixado ou relacionado pelos Conselhos de Educação, e em alguns casos acrescentado pela escola, antes de sua reapresentação, 
nos currículos plenos, sob a forma "didaticamente assimilável" de atividades, áreas de estudo ou disciplinas. (Art. $5^{\circ}$, caput). (BRASIL, 1971b).

Na concepção expressa pela lei 5.692 destacava-se a preocupação didática de tornar o conhecimento assimilável pelo aluno. Dessa forma, deveria ocorrer uma progressão quanto à inserção dos conteúdos específicos das disciplinas ${ }^{10}$. O item Doutrina do Currículo na Lei do Parecer $853 / 71^{11}$ contém uma proposta de escalonamento dos conteúdos de ensino propostos para os diferentes níveis de escolarização, na perspectiva da maior para a menor amplitude do campo de atuação didática, de modo a adequar a abordagem do ensino às diferentes etapas de amadurecimento do aluno com vistas à aquisição do conhecimento. Daí a ideia de diferenciar o currículo por meio de atividades correspondendo a uma aprendizagem que equivaleria às primeiras séries do primeiro grau ou ao antigo primário. Em contrapartida, a área de estudo caracterizada pelas propostas de trabalho com temáticas abrangentes integradoras das matérias, valorizadas especialmente nas séries do ensino de primeiro grau relativas ao antigo ginásio e à disciplina, só aparece no ensino de segundo grau. Nessa concepção, o ensino deveria:

[...] preparar a criança e o jovem para a vida - eis a ótica a ser observada na escola formalmente instituída. As atividades, as áreas de estudo e disciplinas são e serão instrumentos que não valem por si mesmos, mas sim pela possibilidade que oferecem de desenvolver o raciocínio crítico, a lógica, a capacidade de análise e pesquisa-enfim, a capacidade de pensar, de agir e de julgar. (SARAIVA, 1984, p. 88).

Na afirmação da Professora e Conselheira Terezinha Saraiva, é possível perceber a influência dos princípios da Escola Nova quando ressalta, por exemplo, a importância do papel da escola na preparação do jovem para a vida. Durante a entrevista com a professora, em resposta à pergunta sobre se o Parecer 853/71 tinha sido influenciado pela Escola Nova, a conselheira explicou que o documento fora todo elaborado pelo relator Valnir Chagas.

10 Conforme o disposto no Art. 17 da Lei, Capítulo II - Do Ensino de $1^{\circ} \mathrm{Grau:} \mathrm{"O} \mathrm{ensino} \mathrm{de} 1^{\circ} \mathrm{grau}$ destina-se à formação da criança e do pré-adolescente, variando em conteúdo e métodos segundo as fases de desenvolvimento dos alunos".

11 Conselho Federal de Educação. Câmara de Ensino de $1^{\circ}$ e $2^{\circ}$ Graus - Núcleo comum para os currículos do ensino de $1^{\circ}$ e $2^{\circ}$ graus. A doutrina do currículo na Lei $n^{\circ} 5.692$, p.65. 
Chagas, relator do Parecer 853/71 - que contém toda a concepção da reforma de ensino de 1971 - fazia parte do Conselho Federal de Educação desde a década de 60, tendo participado como conselheiro do segundo Grupo de Trabalho (1970), formado para promover a revisão da legislação de ensino. Conforme o depoimento da Prof ${ }^{a}$ Terezinha, além de estudioso das ideias de John Dewey e defensor da adoção dos princípios da Escola Nova no ensino, o relator era também um apreciador das teorias de Piaget, parcialmente integrantes dos conceitos que fundamentam o citado Parecer - como, por exemplo, a divisão em atividades, áreas de estudo e disciplinas adotadas na Lei 5.692, à qual Chagas chama de "divisão tríplice", explicando esse sentido constante da lei:

Na tentativa de acompanhar a evolução psicológica da criança e do adolescente, adota um critério de "amplitude" do campo abrangido pelos conteúdos em conexão com os processos envolvidos na aprendizagem (...) Nas atividades as aprendizagens se desenvolvem antes sobre ações efetivas exercidas em situações concretas - e aí se incluem as habilidades de ler, escrever e contar - que pela sistematização do conhecimento; nas áreas de estudo, o concreto tende a equilibrar-se com o sistemático; e nas disciplinas, sem dúvida a categoria mais específica, as aprendizagens se fazem predominantemente pela sistematização e aplicação de conhecimentos, estabelecendo-se conscientemente o indispensável fluxo entre o saber e o fazer (...) Enquanto a atividade é processo quase puro, algo como alimento pré-digerido para quem não desenvolveu plenamente a capacidade de assimilação, a área de estudo ainda é mais processo que conteúdo e a disciplina é simultaneamente conteúdo e processo. (CHAGAS, 1978, p.197)

Além da influência piagetiana, observamos que a Lei 5.692 incluía também uma concepção a nosso ver muito semelhante à proposta de currículo em espiral de Jerome Bruner. Sob essa visão, no início da sua formação o aluno recebe conceitos básicos que irão prepará-lo para posteriormente entender a matéria formal ou científica, partindo do princípio de que qualquer assunto pode ser trabalhado pelas crianças menores, desde que adaptados ao concreto. Como podemos constatar na concepção exposta no Parecer 853/71,

[...] na sequência de atividades, áreas de estudo e disciplinas, parte-se do mais para o menos amplo e do menos para o mais específico. Além disso, nas atividades, as aprendizagens desen- 
volver-se-ão antes sobre experiências colhidas em situações concretas do que pela apresentação sistemática dos conhecimentos; nas áreas de estudo - formadas pela integração de conteúdos afins, consoante um entendimento que já é tradicional - as situações de experiência tenderão a equilibrar-se com os conhecimentos sistemáticos; e nas disciplinas, sem dúvida as mais específicas, as aprendizagens se farão predominantemente sobre conhecimentos sistemáticos. É, portanto, sobretudo de grau a distinção que se estabelece entre atividade, área de estudo e disciplina, em relação ao jogo situação-conhecimento. Assim como o conhecimento há de estar presente desde a atividade, sob pena de que o ensino a nada conduza, também não se dispensa alguma conexão com o real no estudo das disciplinas, sem o que se descambará para um intelectualismo vazio e inconsistente. (BRASIL, 1971b, p. 69).

A análise do Parecer 853/71 nos permite afirmar que os conselheiros, ao trabalharem com o conceito de amplitude das matérias e criarem o núcleo comum formado por três matérias representando três grandes linhas de estudo do conhecimento humano, apresentavam uma visão de ensino que considera uma diferenciação entre o saber científico ou acadêmico e o saber em sua forma escolarizada, representado hoje pela categoria de análise saber escolar ${ }^{12}$, que leva em conta a existência de uma diferença entre o conhecimento vivenciado na escola e aquele desenvolvido na academia.

O Parecer menciona o "intelectualismo vazio e inconsistente", levando-nos a deduzir que havia um entendimento sobre a diferença entre o conhecimento científico e aquele trabalhado no real, nas situações concretas de aprendizagem vivenciadas na escola, assumindo que certos conhecimentos acadêmicos tornamse improdutivos nesse ambiente.

A ideia de amplitude expressa pelos conselheiros, caracterizada pela gradação na exposição dos conteúdos que serão ensinados, deixava claras a finalidade educacional e a influência da Psicologia. Há uma variação do método de ensino e dos conteúdos para cada nível de aprendizagem. Os conteúdos sistemáticos das

12 "Assim, a perspectiva de constituição de um saber escolar tem por base a compreensão de que a educação escolar não se limita a fazer uma seleção entre o que há disponível da cultura num dado momento histórico, mas tem por função tornar os saberes selecionados efetivamente transmissíveis e assimiláveis. Para isso, exige-se um trabalho de reorganização, reestruturação ou transposição didática que dá origem a configurações cognitivas tipicamente escolares, capazes de compor uma cultura escolar sui generis, com marcas que transcendem os limites da escola". (FORQUIN, 1993, apud MONTEIRO, 2002, p.16-17). 
disciplinas ou-como está no Parecer-"sub-áreas" (matemática, história, geografia, física, português etc...) só apareceriam de forma mais explícita ou predominante no segundo grau. No ensino das primeiras séries do primeiro grau, os conteúdos estão relacionados à experiência e à prática, trabalhados em situações concretas de aprendizagem, em exercícios que despertassem a curiosidade do aluno para a investigação, fornecendo assim os elementos básicos para o método científico.

No segundo segmento do primeiro grau, a proposta era de integração dos conteúdos das disciplinas organizadas por áreas de estudo. Nessa concepção, os conhecimentos das disciplinas estão presentes mas o conteúdo sistemático da disciplina só aparece no segundo grau. Por exemplo, os conhecimentos históricos e geográficos são utilizados, de forma integrada, para atender aos objetivos de adequação do aluno ao meio em que vive e convive socialmente, como podemos comprovar nos objetivos do núcleo-comum inseridos no Parecer 853/71 da Câmara de Ensino de Primeiro e Segundo Graus do Conselho Federal de Educação aprovado em 12.11.1971.

Nessa concepção, há uma intenção clara de integração entre as matérias:

[...] as matérias, diretamente ou por seus conteúdos particulares, devem conjugar-se entre si e com outras que se lhe acrescentem; e para que nada se omitisse, neste particular, também aquela segunda camada logo prescrita no artigo $7^{\circ}$ da lei foi incluída no processo de integração. (BRASIL, 1971b, p.76)

Para exemplificação dessa proposta, o Parecer 853/71 apresenta a figura reproduzida a seguir, que representa dois círculos que se interpenetram, com uma intercessão (linhas pontilhadas) justamente no espaço destinado aos estudos sociais. Nessa interpenetração das matérias, os estudos sociais ocupam a posição central, atuando como um elemento de ligação entre elas. O próprio Parecer 853/71 explica esse sentido:

Com efeito, na medida em que se cogite de uma divisão do conhecimento, e só nessa medida, os Estudos Sociais constituem um elo a ligar as Ciências e as diversas formas de Comunicação e Expressão: têm uma abordagem mais científica do que estas últimas, ao mesmo tempo em que para muitos chegam a confundir-se com elas, e sobretudo colocam no centro do processo a preocupação do Humano. (BRASIL, 1971b, p.75) 
Figura 1 - Os Estudos Sociais como intercessão entre matérias

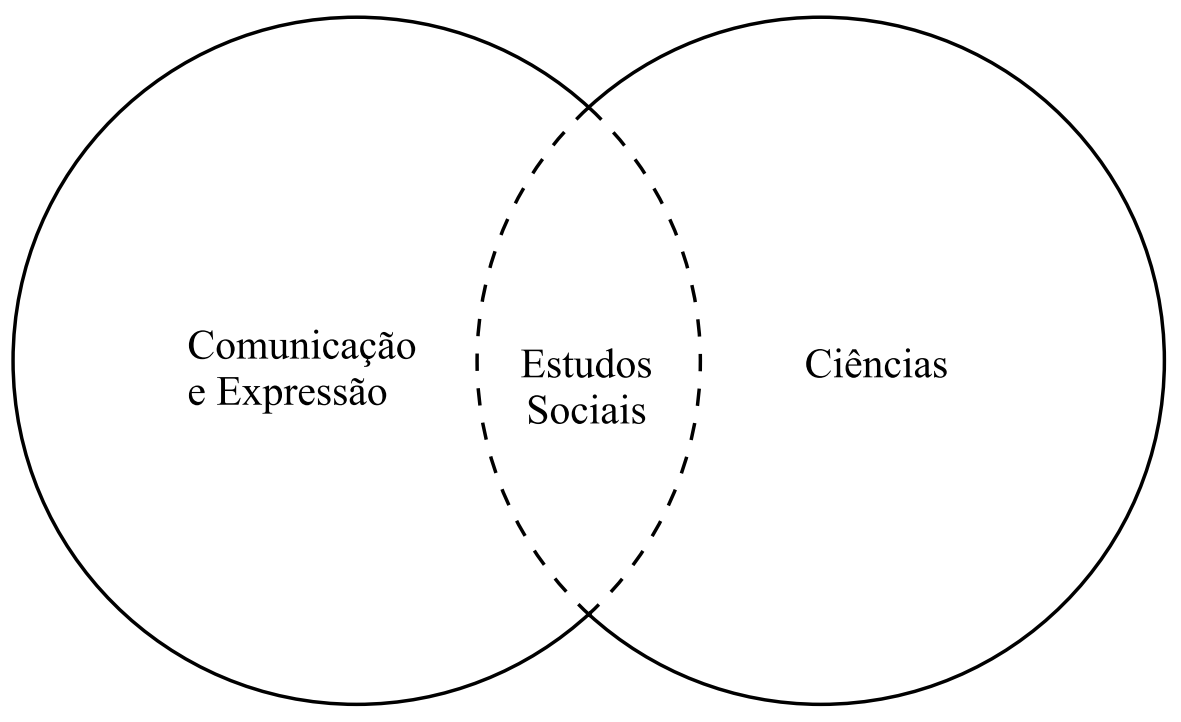

Fonte: (BRASIL , 1971b).

Nessa visão, os Estudos Sociais representavam o aspecto humanístico, o homem como o centro de toda a ação e o sujeito do processo ensino-aprendizagem, além de ratificar os objetivos gerais da educação que, sob tal concepção, visavam ao autoconhecimento e à realização pessoal mediante a interação com a sociedade em que vive, tanto pelo trabalho quanto pela convivência. $O$ foco da educação centrava-se, portanto, no aspecto social.

Quanto aos objetivos das matérias fixadas no Parecer 853/71, cabia aos Estudos Sociais uma função integradora, promovendo o ajustamento do jovem ao meio em que está inserido: "O ajustamento crescente do educando ao meio, cada vez mais amplo e complexo, em que deve não apenas viver como conviver, sem deixar de atribuir a devida ênfase ao conhecimento do Brasil na perspectiva atual do seu desenvolvimento". (BRASIL , 1971b, p. 78).

No texto do Parecer, ficam claras a proposta interdisciplinar e a crítica à autonomia das disciplinas. A construção do currículo escolar, nessa perspectiva integradora, seria o resultado dos conteúdos sistemáticos das disciplinas, trabalhados a partir de projetos criados na escola com o objetivo de desenvolver temáticas específicas. Desse modo, as matérias - com seus conteúdos específicos-eram interligadas umas 
às outras, formando a totalidade do currículo e permitindo assim uma diversidade de currículos, obedecendo às especificidades locais e regionais. Podemos constatar que a integração dos conteúdos no currículo é um princípio fundamental na Lei 5.692.

Cabe destacar que, nessa proposta teórico-metodológica, prevalecia a concepção integradora do núcleo como elemento fundamental para "o preparo ao exercício consciente da cidadania", como vimos acima. Assim, os conteúdos particulares e obrigatórios das grandes linhas de matérias tornavam-se meios para promover a interação entre elas.

Nessa visão interdisciplinar, o ensino da Língua Portuguesa, por exemplo, além da sua função instrumental, deveria valorizar o sentido da cultura brasileira, articulando a Literatura com a História e a Geografia para promover a compreensão dos valores culturais que constituíram o contexto atual da civilização brasileira, sem negar as origens europeias e o contexto da História Universal no qual estamos inseridos. O ensino priorizava o estudo do meio físico e social brasileiro e as questões contemporâneas:

Os Estudos Sociais cujo objetivo é a integração espacio-temporal e social do educando em âmbitos gradativamente mais amplos. Os seus componentes básicos são a Geografia e a História, focalizando-se na primeira a Terra e os fenômenos naturais referidos à experiência humana, e, na segunda, o desenrolar dessa experiência através dos tempos. O fulcro do ensino, a começar pelo "estudo do meio", estará no aqui-e-agora do mundo em que vivemos e, particularmente, do Brasil e do seu desenvolvimento. (BRASIL, 1971b, p. 80)

O objetivo do ensino era priorizar o Brasil, porém ficava expresso que o conhecimento de outros povos e da experiência humana como um todo era fundamental para situar o homem no mundo em que vive. A interação entre os conteúdos das matérias seria fundamental para dar conta desse aprendizado, voltado para um contexto global.

Segundo a Prof ${ }^{\mathrm{a}}$ Terezinha Saraiva, o Parecer 853/71:

"Foi o primeiro parecer depois da lei. Eu me recordo muito bem, pois já fazia parte do Conselho. A Lei foi promulgada em 11 de agosto de 1971, e eu fazia parte da mesma Câmara do Valnir. Era 
a Câmara de Primeiro e Segundo Graus. O Padre José Vasconcelos era o presidente. Faziam parte também, Ester Figueiredo Ferraz, Paulo Nathanael Pereira de Souza, Valnir Chagas e eu. Nós participamos da Câmara de Primeiro e Segundo graus desde 1970 até 1980 quando eu saí. Durante os seis últimos anos assumi a presidência da Câmara de $1^{\circ}$ e $2^{\circ}$ Graus em substituição ao Conselheiro Padre José Vieira de Vasconcelos, porque ele assumiu a presidência do Conselho Federal de Educação. Assim que a lei foi promulgada, nas reuniões de Câmara, o Valnir dizia que a primeira coisa que devíamos tratar é desta parte do "Núcleo comum", pois é algo totalmente novo e vai mexer com muita coisa e fez questão de ser o relator desse parecer."

A conselheira destaca, ainda, que não houve interferência política ou militar na elaboração do mesmo:

“... posso assegurar: que durante os dez anos, de 1970 a 1980, em que fui conselheira, nunca houve qualquer interferência no Conselho Federal de Educação, nem do Ministro da Educação, nem dos militares. Mesmo depois que o Ministro Passarinho já deixara o Ministério nós tínhamos estabelecido uma relação tão cordial, tão respeitosa, tão amiga que nos reuníamos com ele e sua esposa Ruth para jantarmos quase todos os meses. O Conselho Federal de Educação não era subordinado ao Ministério. Constituía-se num poder paralelo. Era o órgão normativo do Ministério da Educação. Havia uma relação muito cordial e amistosa. Durante algum tempo o que se viu foi o Ministro da Educação interferindo no Conselho. Naquela época nenhum interferia... Eu acompanhei toda a elaboração da Lei 5692 e posso garantir que nunca houve nenhuma interferência. O Ministro Passarinho nunca fez interferência, nem teve qualquer influência para alterar o Anteprojeto.

O ministro Passarinho nunca fez interferência, nem colocou nenhuma palavra sobre a lei. De modo geral os ministros nunca interferiam no período em que eu estive no conselho. Às vezes ele pedia algum estudo ou parecer, mas tudo relacionado ao ensino, que chegava para o ministro, era encaminhado para o conselho para ser estudado. Competia ao ministro homologar ou não, mas quem fazia o estudo era o conselho. O Conselho era um órgão normativo do sistema federal de ensino." 
A análise do Parecer 853/71 e do depoimento da Prof ${ }^{\mathrm{a}}$ Terezinha Saraiva nos permitem concluir que muitas das concepções e princípios expostos na Lei 5.692 foram defendidos ao longo da década de 60 e consolidados em 1971. A proposta de integração entre as disciplinas, assim como a perspectiva de uma educação individual e social com vistas à preparação do aluno para a vida em sociedade, são similares àquelas defendidas por alguns membros do Conselho Federal de Educação durante a década de 60 .

A análise dos depoimentos da Prof ${ }^{a}$ Terezinha, bem como os documentos do período, mostram que não houve uma ruptura entre as ideias pedagógicas desenvolvidas na década de 60 e as propostas encontradas na Lei de Diretrizes e Bases de 1971. Os estudos que antecederam à elaboração da Lei, desenvolvidos pelos Grupos de Trabalho em 1969 e 1970, foram realizados por membros do antigo Conselho Federal de Educação e englobaram muitas das ideias ali defendidas. Como exemplo, temos o Parecer 853/71 cujo relator - Valnir Chagas - compartilhava do ideal escolanovista de Anísio Teixeira e Newton Sucupira, seus companheiros no Conselho ao longo de toda a década de 60. A análise nos permite destacar, também, que os membros do Conselho Federal de Educação na década de 70 tinham trajetória reconhecida no campo educacional. O depoimento da Prof ${ }^{a}$ Terezinha Saraiva nos leva a afirmar que Valnir Chagas incluiu no parecer todas as ideias anteriormente construídas, inclusive a proposta dos Estudos Sociais que fora gestada durante a década de 60, e que foi inserida como disciplina optativa, por determinação do Conselho Estadual de Educação, nos currículos do ginásio - como já vimos anteriormente - e que por iniciativa do Conselho Federal de Educação foram criadas as Licenciaturas em Estudos Sociais, por meio do Parecer 106/66. Nesse sentido, perguntei à conselheira se fora pensada alguma preparação para se trabalhar com os Estudos Sociais, obtendo a seguinte resposta:

"Não. Porque isso era uma questão do âmbito estadual, uma vez que o responsável pelo ensino fundamental e médio era o sistema estadual. O que competia ao Conselho Federal era propor a licenciatura para poder interferir na formação do professor, que lecionaria aquela matéria e não mais das disciplinas história e geografia. As licenciaturas deveriam preparar os professores para lecionar a matéria Estudos Sociais, através de atividades, áreas de estudo no ensino de primeiro grau e, no segundo grau, as disciplinas - História, Geografia , OSPB.” 
A professora explicou que as propostas de licenciatura curta da década de 1960 saíam do Conselho, oriundas dos conselheiros que já pensavam em fazer uma proposta de ensino que precisaria de uma licenciatura, e que, embora não estivesse explícito no bojo da Lei, a proposta está contida no texto do Parecer, segundo a educadora:

"O interesse do Conselheiro Valnir em relatar o parecer demonstra que isso já estava no pensamento dele."

Concordamos, portanto, com o pensamento da professora de que a concepção pedagógica inserida na Lei, especialmente no que se refere aos Estudos Sociais, foi construída ao longo da década de 60 - quando faziam parte do Conselho Federal de Educação nomes bastante ligados à Escola Nova e a uma proposta progressista de ensino, como Anísio Teixeira, Newton Sucupira e Valnir Chagas. Tal proposta teve continuidade e se consolidou nas diretrizes da reforma educacional de 1971 (LDB 5.692).

Acompanhando os acontecimentos, sente-se que a necessidade de uma nova lei não resultou de uma decisão de momento, mas de dados, pareceres do Conselho Federal de Educação e reflexões dos educadores, que se somaram ao longo do tempo, indicando necessidade de reformulações. (SARAIVA, 1984, p.18)

A análise do Parecer 853/71 nos permite concluir, também, que a proposta da Reforma Educacional contida na Lei 5.692, ao agrupar em Estudos Sociais as disciplinas História e Geografia no currículo do primeiro grau, criava uma matéria escolar. Os Estudos Sociais, desde sua origem nos estudos da Escola Nova até sua implementação experimental, no Brasil, ao longo da década de 60 , representaram uma matéria para a escola, dentro da ideia de integração dos conteúdos para atender a objetivos exclusivamente escolares.

O sentido do termo "matéria" como um conjunto de conteúdos de diferentes disciplinas de uma área, trabalhados na escola de forma integrada para dar conta do projeto de ensino específico daquele estabelecimento de ensino, exposto no Parecer 853/71, ratifica essa dedução.

Concluímos, com base no estudo, que a criação da disciplina escolar Estudos Sociais não resultou da interferência ou teve qualquer relação com o governo 
militar. A resistência e crítica suscitadas expressam embates entre concepções sobre currículo e tradições estabelecidas com repercussões sobre a formação de professores. O contexto histórico no qual esse processo se desenvolveu, período de autoritarismo político no âmbito do regime militar, tornou-se um campo de possibilidades para a produção de diferenciadas interpretações sobre a proposta, que passou a ser vista pelos professores de História como ação política com o objetivo de esvaziar a formação para a cidadania em perspectiva histórica e crítica.

\section{Referências}

CHAGAS, V. Educação Brasileira: o ensino de $1^{\circ}$ e $2^{\circ}$ graus: antes, agora e depois?. São Paulo: Editora Saraiva, 1978.

MONTEIRO, A. M. F. da Costa. Ensino de História: entre saberes e práticas. 2002. Tese (Doutorado)-Programa de Pós-Graduação em Educação, Pontifícia Universidade Católica do Rio de Janeiro, Rio de Janeiro, 2002.

SARAIVA, T Educação: temas para debate. Rio de Janeiro: BLOCH Editores, 1984.

Caminhos trilhados: reflexões e fazeres. Rio de Janeiro: Editora e Livraria Espaço do Saber, 2004.

BRASIL. Lei no 4.024 de 20 de dezembro de 1961. Fixa as diretrizes e bases da educação nacional. Diário Oficial da União, Brasília, DF, 27 dez. 1961. Seção 1, p.11429.

Lei $\mathrm{n}^{\mathrm{o}} 5.692$, de 11 de agosto de 1971. Fixa diretrizes e bases para o ensino de $1^{\circ}$ e $2^{\circ}$ graus, e dá outras providências. Diário Oficial da União, Brasília, DF, 12 ago. 1971.

Parecer $\mathrm{n}^{\circ} 853$ de 12 de novembro de 1971. Núcleo comum para os currículos do ensino de $1^{\circ}$ e $2^{\circ}$ graus. A doutrina do currículo na Lei n. 5.692. In: Documenta $n^{\circ} 132$, Rio de Janeiro, nov. 1971b.

Recebido em: 21/05/2012

Aceito para publicação: 14/06/2013 


\section{The curriculum of brazilian schools in the 1970: new historical perspectives Abstract}

Based on the Law of Guidelines and Bases for Education $N^{\circ}$ 5.692, August 11, 1971 and Evaluation 853/1971, this article presents a historical search-documentary developed in the Graduate Education Program at the Federal University of Rio de Janeiro. It analyses the pedagogical ideas developed through the sixties, under the influence of New School educators and their contribution to the fundaments of the Education Reform that included the discipline in the curriculum of our primary and secondary schools. Deriving from a new historiographical perspective made possible by detachment, this survey found that the introduction of Social Studies in elementary school teaching corresponded to a branch of the legislation under the Federal Education Council, in force since 1966. The composition of the Board members in the sixties, including major names of the New School in Brazil, reinforces the idea that Social Studies as part of the curriculum was based on a predominantly pedagogical issue.

Keywords: Curriculum. School Subjects. New School. Social Studies

\section{El currículo de las escuelas brasileñas en la década de 1970: nuevas perspectivas historiográficas Resumen}

Fundamentado en la Ley $n^{\circ}$ 5.692, de 11 de agosto de 1971, que fijó las Directrices y Bases para la enseñanza de $1^{\circ}$ y $2^{\circ}$ grados y en el Parecer 853/71, este artículo presenta una investigación histórico-documental desarrollada en el Programa de Pos-graduación en Educación, en la Universidad Federal de Río de Janeiro. Se trata de un análisis de las ideas pedagógicas desarrolladas al largo de la década de 1960, bajo la influencia de los educadores de la Escuela Nueva, y su contribución en los fundamentos de la Reforma Educacional, que incluyó la disciplina en el currículo de $1^{\circ}$ y $2^{\circ}$ grado de nuestras escuelas. A partir de una nueva perspectiva historiográfica que el distanciamiento hace posible, esta investigación constató que la implantación de los Estudios Sociales en la enseñanza de primer grado reflejó un desdobramento de la legislación del Consejo Federal de Educación, en vigor desde 1966. La composición del Consejo en la década de 60, incluyendo nombres significativos de la Escuela Nueva en Brasil, vino a confirmar que la adopción de los Estudios Sociales como disciplina en el currículo se basó en una cuestión eminentemente pedagógica. Palabras clave: Currículo. Disciplinas Escolares. Escuela Nueva. Estudios Sociales. 